Acta Crystallographica Section D

Biological

Crystallography

ISSN 0907-4449

Edward N. Baker ${ }^{\mathrm{a} *}$ and Zbigniew Dauter $^{b_{*}}$

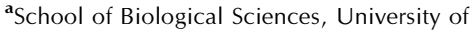
Auckland, Private Bag 92-019, Auckland, New Zealand, and ${ }^{\mathbf{b}}$ Argonne National Laboratory, Biosciences Division, Bldg 202, Room Q142, Argonne, IL 60439, USA

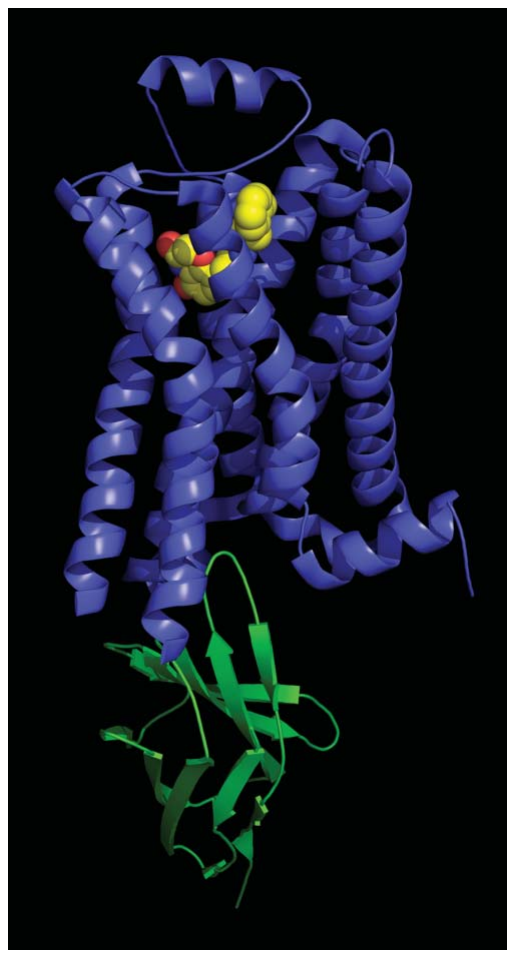

Cartoon of the structure of the $\beta 2$ adrenergic receptor GPCR (blue), with an inserted camelid antibody domain (green) and a bound ligand carazolol (yellow), solved by Brian Kobilka and colleagues.

\section{Nobel Prize for Chemistry 2012: GPCRs seen through a crystal ball}

The award of a Nobel Prize provides an opportunity to celebrate the special excitement of scientific discovery. The immediate glory deservedly goes to select individuals who have pioneered a field, been responsible for a landmark discovery or had some extraordinary insight. Some inevitably miss out on the prize, but many share in the pleasure - graduate students, postdocs, colleagues, friends, family and others connected through the science itself.

This year's Nobel Prize in Chemistry goes to Robert Lefkowitz and Brian Kobilka for their ground-breaking studies of G-protein-coupled receptors. These molecules reside in biological membranes, where they sense external signals, predominantly chemical, and trigger cascades of events inside cells. They are responsible for sight, smell and taste, for the regulation of heart rate and blood pressure, and they are the targets of nearly half of all therapeutic drugs. They are also very challenging beasts, with flexible parts and subtle changes in conformation that are inextricably linked to how they act.

This Nobel Prize honours many things: the importance of GPCRs, the ingenuity and persistence of the researchers, the vision to recognize the routes to success. Brian Kobilka's crystallographic studies, spanning more than 20 years, required highly innovative approaches before crystals of the required quality could be obtained. These included the use of a 'nanobody' (camelid antibody domain) to stabilise an active conformation, insertion of T4 lysozyme into a flexible loop, and use of cubic lipidic phase technology. It also required 'minibeam' technologies only available with synchrotron radiation and the powerful methods of modern macromolecular crystallography. The result has been a series of atomic models that give exquisite detail on GPCR function (Cherezov et al., 2007; Rosenbaum et al., 2007; Rasmussen et al., 2011a,b). And it has galvanized the field as more GPCRs, in their varied conformations, now yield to crystallography.

Reflected glory, too, goes to crystallography. Should we be surprised? Perhaps not, because crystallography gives such a unique window into the natural world, providing an atomic view of materials, whether they be the complex molecules of biology or the clever constructs of chemistry and materials science. This year's Nobel Prize is the latest in more than 20 that have been awarded for crystallography or have depended heavily upon it (see the IUCr website http:// www.iucr.org). Our own mentor, Dorothy Hodgkin, Nobel Laureate in 1964, would be thrilled! The atomic structure also powerfully connects biology to chemistry; as Venki Ramakrishnan (2009 Nobel Prizewinner with Tom Steitz and Ada Yonath for solution of the ribosome structure) said 'ultimately, when you look at any biological question it becomes a chemical problem'.

Appropriately, this year, 2012, is also a very special one for crystallography. We celebrate 100 years since two events made this whole field of science possible; the discovery of X-ray diffraction by Max von Laue in April 1912 and the realization by Lawrence Bragg, only three months later, that by reformulating the phenomenon the door was opened to structure determination. von Laue's experiment was celebrated in a special symposium of the German Crystallographic Society in March this year, and Bragg's insight will be celebrated in December at the joint meeting of the Asian Crystallographic Association and the 
Society of Crystallographers in Australia and New Zealand. With the United Nations designating 2014 as the International Year of Crystallography, there is much to celebrate. This year's Nobel Prize is more icing on the cake.

\section{References}

Cherezov, V. et al. (2007). Science, 318, 1258-1265.

Rosenbaum, D. M. et al. (2007). Science, 318, 1266-1273.

Rasmussen, S. G. F. et al. (2011). Nature (London), 469, 175-180.

Rasmussen, S. G. et al. (2011). Nature (London), 477, 549-555. 